\title{
INDIVIDUAL OVERTOPPING EVENTS AT DIKES
}

\author{
Gijs Bosman ${ }^{1}$, Jentsje van der Meer ${ }^{2}$, Gijs Hoffmans ${ }^{3}$, Holger \\ Schüttrumpf ${ }^{4}$ and Henk Jan Verhagen ${ }^{5}$
}

\begin{abstract}
Recently, formulae have been derived for maximum flow depths and velocities on the crest and inner slope of dikes or levees at wave overtopping. Two independent physical model test programs in different wave flumes showed, however, a large difference in the results. The present paper clarifies this discrepancy and shows that the empirical coefficients are dependent on the gradient of the outer slope. Subsequently, a formula for the overtopping time was created, based on the difference between fictive wave run-up and crest freeboard. The overtopping time appeared not to be a function of the outer slope. The variation of flow depth and velocity in time can be approached with a linear function.
\end{abstract}

\section{INTRODUCTION}

In the new Overtopping Manual (2007), equations are presented for wave run-up, mean discharge, individual overtopping volumes and maximum velocities and flow depths of overtopping waves at the crest of a dike or levee. The hydraulic part of wave overtopping on a dike is fairly well-defined, but during the development of the wave overtopping simulator, as described in Van der Meer et al., (2006), it became clear that very specific points on individual overtopping events were not clear or not described at all.

\section{FORMER STUDIES}

Studies have been carried out to determine overtopping velocities and flow depths during wave overtopping. Schüttrumpf (2001b) and Van Gent (2002) give formulae for the maximum velocity and maximum flow depth on the crest and the inner slope of a dike. The theories are based on the difference between the fictive $2 \%$ wave run-up $z_{2} \%$ and the crest freeboard $R_{c}$, indicated with the letter $A$ in Figure 1. In fact is $A$ the remainder of the wave run-up and an initial measure to quantify the flow depths and velocities on the crest, thus the larger the remainder of the run-up, the larger the velocities and flow depths.

\footnotetext{
${ }^{1}$ Royal Haskoning, George Hintzenweg 85, 3068 AX Rotterdam, The Netherlands

${ }^{2}$ Van der Meer Consulting, Voorsterweg 28, 8316 PT Heerenveen, The Netherlands

${ }^{3}$ Deltares, Rotterdamseweg 185, 2629 HD Delft, The Netherlands

${ }^{4}$ Institute of Hydraulic Engineering and Water Resources Management, RWTH Aachen

University, Mies-van-der-Rohe Strasse 1, D-52056 Aachen, Germany

${ }^{5}$ Section Hydraulic Engineering and Geosciences, Delft University of Technology, Stevinweg 1, 2628 CN Delft, The Netherlands
} 


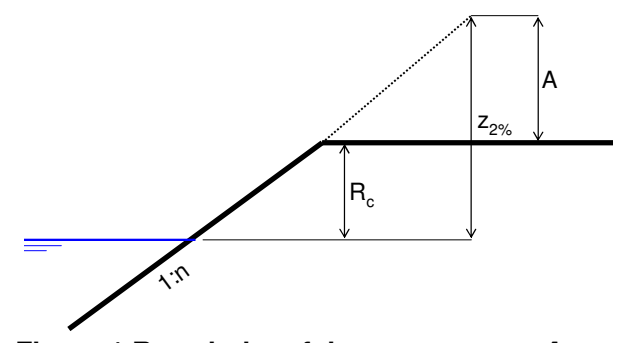

Figure 1 Remainder of the wave run-up $A$

\section{Seaward side of the crest}

The general formulae for maximum flow depth and maximum flow velocity at the seaward side of the crest have been described in Schüttrumpf and Van Gent (2003), see equations 1 and 2.

$$
\begin{aligned}
& \frac{h_{2 \%}\left(x_{c}=0\right)}{H_{s}}=c_{h, 2 \%}^{\prime}\left(\frac{z_{2 \%}-R_{c}}{\gamma_{f} H_{s}}\right)^{0.5} \\
& \frac{u_{2 \%}\left(x_{c}=0\right)}{\sqrt{g H_{s}}}=c_{u, 2 \%}^{\prime}\left(\frac{z_{2 \%}-R_{c}}{\gamma_{f} H_{s}}\right)^{0.5}
\end{aligned}
$$

Where:

$h_{2 \%} \quad=$ maximum flow depth exceeded by $2 \%$ of the incident waves [m]

$u_{2 \%} \quad=$ maximum velocity exceeded by $2 \%$ of the incident waves $[\mathrm{m} / \mathrm{s}]$

$\begin{array}{lll}x_{c} & =\mathrm{x} \text {-coordinate on the crest } & {[\mathrm{m}]}\end{array}$

$c_{h, 2 \%}^{\prime} \quad=$ empirical coefficient $[-]$

$c^{\prime}{ }_{u, 2 \%}=$ empirical coefficient $[-]$

$\gamma_{f} \quad=$ influence factor for the roughness on the outer slope $\quad[-]$

The coefficients $c^{\prime}{ }_{h, 2 \%}$ and $c^{\prime}{ }_{h, 2 \%}$ have been determined by Schüttrumpf and Van Gent in different physical model tests. The values are listed in Table 1.

\begin{tabular}{|c|c|c|}
\hline \multicolumn{3}{|c|}{ Table 1. Coefficients of Schüttrumpf and Van Gent at the seaward side of the crest } \\
\hline & Schüttrumpf et al. (2001b) & Van Gent (2002) \\
\hline$c_{h, 2 \%}^{\prime}$ & 0.33 & 0.15 \\
\hline$c_{u, 2 \%}^{\prime}$ & 1.37 & 1.30 \\
\hline
\end{tabular}

\section{Influence of the crest and inner slope}

On the crest the general formulae can be described by equations 3 and 4 .

$$
\frac{h_{2 \%}\left(x_{c}\right)}{h_{2 \%}\left(x_{c}=0\right)}=\exp \left(-c_{h, 2 \%}^{\prime \prime} \frac{x_{c}}{B_{c}}\right)
$$




$$
\frac{u_{2 \%}\left(x_{c}\right)}{u_{2 \%}\left(x_{c}=0\right)}=\exp \left(-c_{u, 2 \%}^{\prime \prime} \frac{x_{c} \cdot f}{h_{2 \%}\left(x_{c}\right)}\right)
$$

Where:

$$
\begin{array}{llr}
c^{\prime \prime}{ }_{h, 2 \%} & =\text { empirical coefficient } & {[-]} \\
c^{\prime \prime}{ }_{u, 2 \%} & =\text { empirical coefficient } & {[-]} \\
B_{c} & =\text { crest width } & {[\mathrm{m}]} \\
f & =\text { friction coefficient (= 0.02 for smooth coverage and grass) } & {[-]}
\end{array}
$$

The empirical coefficients determined by Schüttrumpf and Van Gent are listed in Table 2.

\begin{tabular}{|c|c|c|}
\hline \multicolumn{3}{|c|}{ Table 2. Coefficients of Schüttrumpf and Van Gent at the landward side of the crest } \\
\hline & Schüttrumpf et al. (2001b) & Van Gent (2002) \\
\hline$c^{\prime \prime}{ }_{h, 2} \%$ & 0.89 & 0.40 \\
\hline$c^{\prime \prime}{ }_{u, 2 \%}$ & 0.5 & 0.5 \\
\hline
\end{tabular}

On the inner slope Schüttrumpf uses a Navier-Stokes equation and Van Gent a One-dimensional shallow water equation. The One-dimensional shallow water equation is preferred above the Navier-Stokes equation, Schüttrumpf and Van Gent (2003), because the last mentioned equation has to be solved iteratively while the One-dimensional equation is even easier to use for practical solutions.

\section{Discrepancy in test results}

Table 1 shows a large difference that attracts the attention. The empirical coefficient of the flow depth equation was determined to be a factor 2.2 larger by Schüttrumpf than by Van Gent. They are similar for the empirical coefficient of the velocity equation. According to Schüttrumpf and Van Gent the discrepancy between the results can be explained by different model set-ups ('different dike geometries and instruments') and test programs, Schüttrumpf and Van Gent (2003). The next section will focus on these differences between the experiments. Also the data-processing in both studies will be analysed.

\section{DATA AND RELIABILITY}

Data of measured velocities and flow depths on the crest and inner slope were available from both physical model tests. With this data the reliability of the measurements was analysed first. It was concluded that the velocities measured during the large scale tests by Schüttrumpf were not always correct. The velocity of high turbulent, non stationary, air containing flow appeared to be very difficult to measure. Figure 2 shows the relation between the front velocity and the mean maximum velocity. The front velocity is the time that the front of the overtopping wave travels between two locations on the crest, this is compared with the mean of the maximum velocities measured on the same locations on the crest. Velocities above $2.5 \mathrm{~m} / \mathrm{s}$ were not recorded, The empirical 
velocity coefficient found by Schüttrumpf is therefore too low. For that matter not only the flow depths, but also the velocities that occurred during the tests of Schüttrumpf were higher than in Van Gent's tests. In the present study the empirical coefficient $c^{\prime}{ }_{{ }_{2} \%}$ has been recalculated for the tests of Schüttrumpf, using the front velocities, and was $c^{\prime}{ }_{u 2 \%}=1.64$.

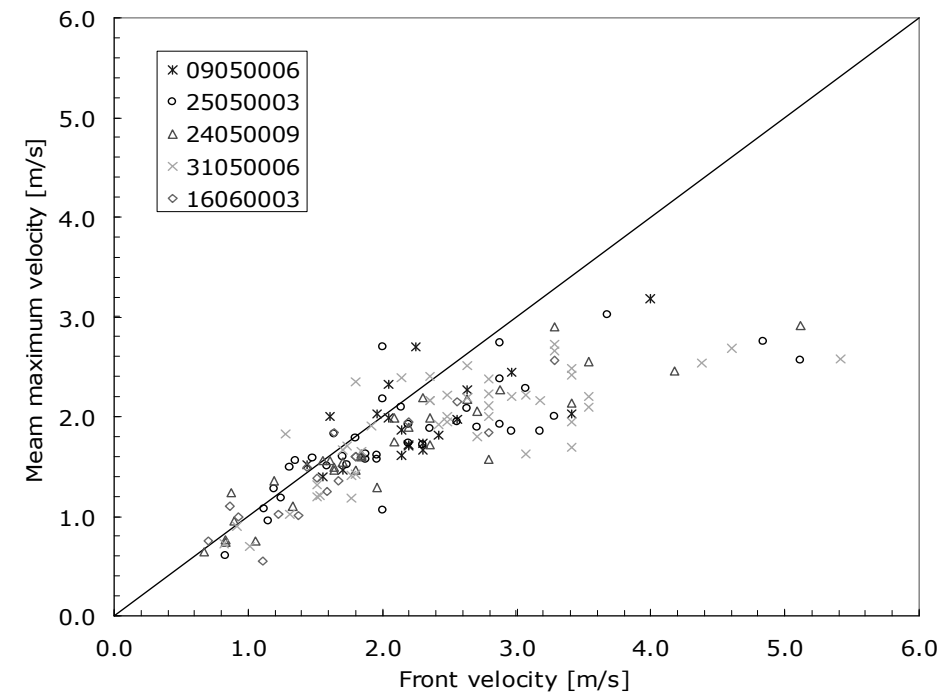

Figure 2. Front velocities against mean maximum velocities in Schüttrumpf's tests

\section{MAXIMUM FLOW DEPTH AND VELOCITY}

\section{The influence of the outer slope}

Schüttrumpf and Van Gent (2003) conducted experiments on dikes with different outer slopes. Schüttrumpf used an outer slope of 1:6 and Van Gent 1:4. The formulae for maximum flow depth and maximum velocity on the crest have been based on the remainder of the wave run-up, $A$ : the $2 \%$ run-up level minus the crest freeboard. This has been defined in vertical direction, see also Figure 1. When a smooth slope is assumed, therefore only the gravitational force limits the wave run-up height.

An example is used to describe the influence of the outer slope on the velocity and flow depth of the overtopping water. Table 3 gives overtopping parameters for two different dike configurations. The parameters have been determined for one wave characteristic and two different outer slopes.

\begin{tabular}{|l|l|l|l|l|l|l|l|l|l|l|}
\hline \multicolumn{10}{|l|}{ Table 3. Example with one wave and two different outer slopes } \\
\hline $\begin{array}{l}\text { Dike } \\
\text { configuration }\end{array}$ & Slope & $\begin{array}{l}\alpha \\
{\left[{ }^{\circ}\right]}\end{array}$ & $\begin{array}{l}H_{s} \\
{[\mathrm{~m}]}\end{array}$ & $\begin{array}{l}T \\
{[\mathrm{~s}]}\end{array}$ & $\begin{array}{l}\mathrm{S}_{\mathrm{om}} \\
{[-]}\end{array}$ & $\begin{array}{l}\xi \\
{[-]}\end{array}$ & $\begin{array}{l}z_{2 \%} \\
{[\mathrm{~m}]}\end{array}$ & $\begin{array}{l}\text { slope } \\
{[\mathrm{m}]}\end{array}$ & $\begin{array}{l}R_{\mathrm{c}} \\
{[\mathrm{m}]}\end{array}$ & $\begin{array}{l}A \\
{[\mathrm{~m}]}\end{array}$ \\
\hline$(1)$ & $1: 4$ & 14.0 & 1 & 5 & 0.026 & 1.56 & 2.58 & 10.6 & 1.58 & 1.0 \\
\hline$(2)$ & $1: 6$ & 9.46 & 1 & 5 & 0.026 & 1.04 & 1.72 & 10.5 & 0.72 & 1.0 \\
\hline
\end{tabular}


The crest freeboards have been chosen in such a way that the remainder of the wave run-up $A$ will be equal for both dike configurations. The lengths of the slopes of the $2 \%$ run-up values $s$ will almost be equal as well (around $10.5 \mathrm{~m}$, see the $9^{\text {th }}$ column). This situation has been drawn in Figure 3.

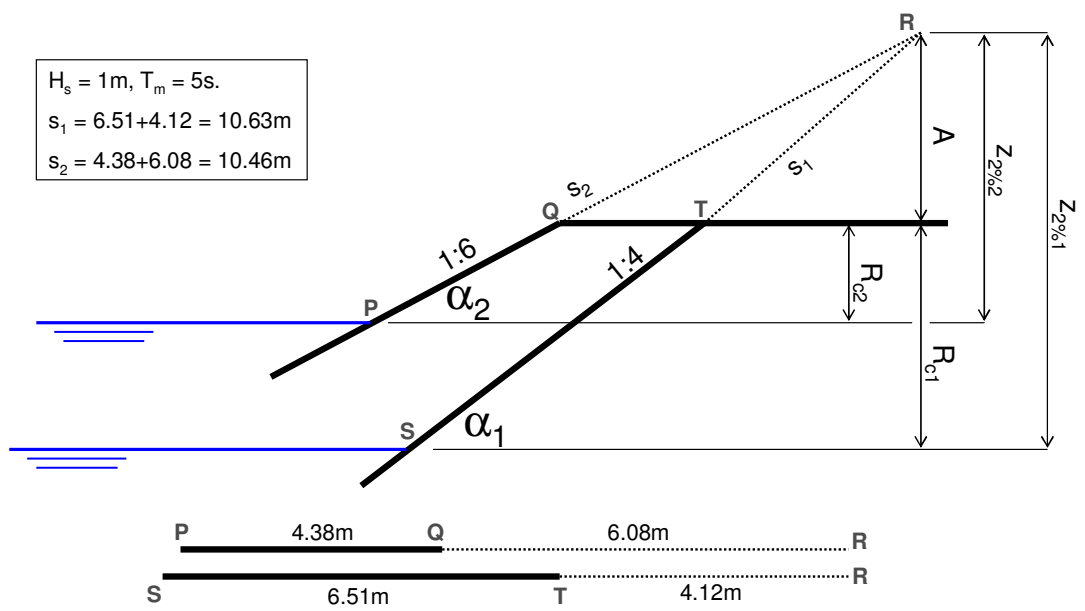

Figure 3. Situation sketch for a wave generating the same remainder of the wave run-up at two dikes with a different outer slope

The vertical wave run-up $z_{2} \%$ for dike configuration (1) will be much higher than the $z_{2 \%}$ for configuration (2). That means that the vertical velocity component of the water in point $S$ will also be higher than in point $P$ in order to achieve the top, point $R$. The vertical velocity component in points $Q$ and $T$ will be the same, because the vertical distance to point $R$ is also the same from these points. The velocity along the slope in points $Q$ and $T$ will not be the same, see also Fig. 4.

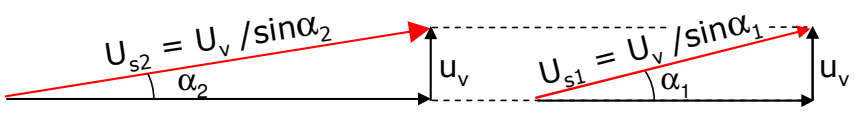

Figure 4. Velocity along the outer slope for two dike different configurations with the same vertical velocity components

With the use of Figures 3 and 4, Eq 5 can be formulated for point $Q$ and $T$ :

$$
u_{v}=u_{s 1} \sin \alpha_{1}=u_{s 2} \sin \alpha_{2} \rightarrow \frac{u_{s 1}}{u_{s 2}}=\frac{\sin \alpha_{2}}{\sin \alpha_{1}}
$$

Where:

$u_{v}=$ vertical velocity component

$u_{s}=$ velocity component along the inner slope 
In the example is $\sin \alpha_{2} / \sin \alpha_{1}=0.68$, this means that $u_{s 1}=0.68 \cdot u_{s 2}$ or $u_{s 2}=$ $1.47 \cdot u_{s l}$. Thus the velocity is almost 1.5 times larger at point $Q$ in comparison to point $T$ in the direction along the slope (in Figure 4).

This phenomenon influences the velocities on the crest during wave overtopping. The empirical coefficient $c^{\prime}{ }_{u, 2} \%$ has to be a function of the outer slope angle, equation 6 , with ' $a$ ' being an empirical coefficient.

$$
c_{u, 2 \%}^{\prime}=\frac{a}{\sin \alpha}
$$

The relation between the maximum velocity and maximum flow depth is described below in equation 7 and will be used to determine coefficient $a$ of equation 6 . The relation has been determined by substituting equations 1 and 2 , details of the derivation of those equations are described by Schüttrumpf (2001a).

$$
\left.\begin{array}{l}
\frac{u_{2 \%}}{\sqrt{g H_{s}}}=c_{u, 2 \%}^{\prime}\left(\frac{A}{H_{s}}\right)^{0.5} \\
\frac{h_{2 \%}}{H_{s}}=c_{h .2 \%}^{\prime} \frac{A}{H_{s}}
\end{array}\right\} \frac{u_{2 \%}}{\sqrt{g H_{s}}}=b \sqrt{\frac{h_{2 \%}}{H_{s}}} \rightarrow c_{u, 2 \%}^{\prime}\left(\frac{A}{H_{s}}\right)^{0.5}=b\left(c_{h .2 \%}^{\prime} \frac{A}{H_{s}}\right)^{0.5}
$$

Where:

$b \quad=$ scaling factor

It is assumed that the relation between flow depth and velocity must be scaled with a factor $b$. The relation between the coefficients can be written as:

$$
c_{h .2 \%}^{\prime}=\left(\frac{c_{u, 2 \%}^{\prime}}{b}\right)^{2}=\left(\frac{a}{b \sin \alpha}\right)^{2}=\frac{a^{2}}{b^{2} \sin ^{2} \alpha}
$$

The coefficient $c^{\prime}{ }_{h, 2 \%}$ showed a discrepancy of 2.2 between the studies of Schüttrumpf and Van Gent $(0.33 / 015=2.2)$. This matches with equation 8 , because:

$$
\frac{\sin ^{2} \alpha_{1}}{\sin ^{2} \alpha_{2}}=\frac{\sin ^{2}(9.46)}{\sin ^{2}(14.0)}=2.2
$$

This means that the flow depth coefficient is related to the outer slope angle raised to the square. The flow depth on the outer slope can be drawn for both dike configurations on the moment the maximum (fictive) wave-run up is reached, see Figure 6. 


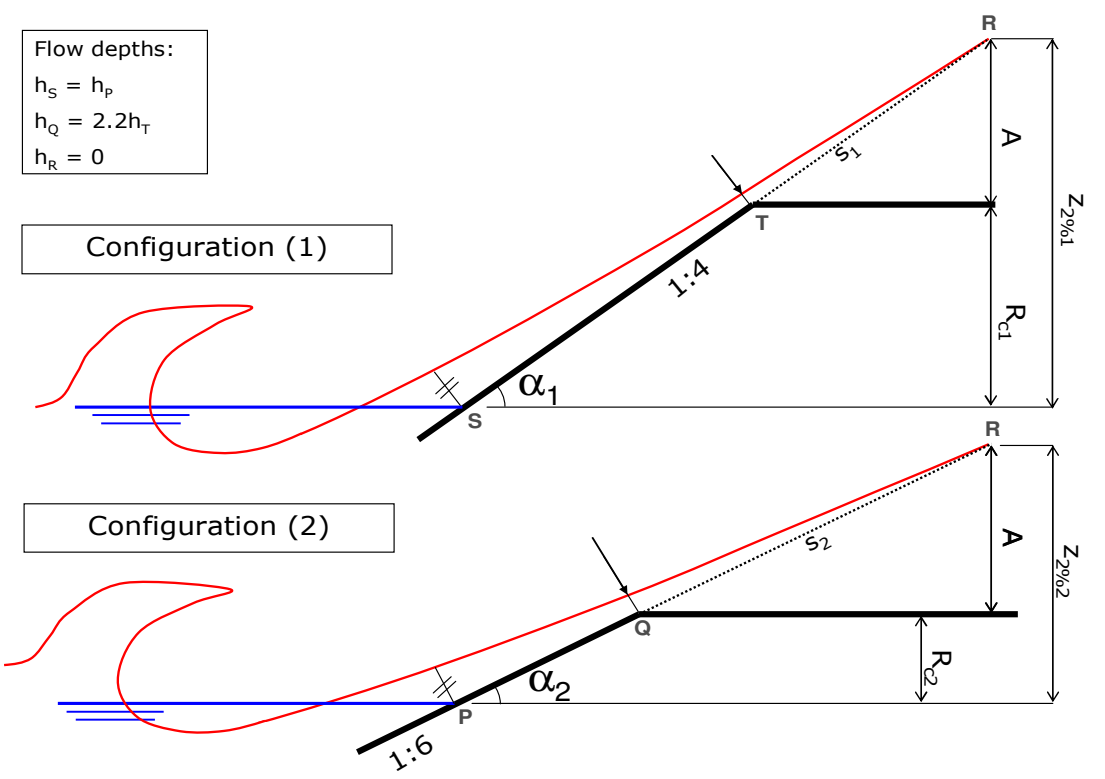

Figure 6. Fictive wave run-up on the outer slope for two dike configurations

The following two assumptions have been made (see Figure 6):

1. The flow depth on the outer slope at the position of MSL $(\eta=0)$ will be equal for both dike configurations: $h_{P}=h_{S}$.

2. The shape of the tongue of water on the outer slope is curved ${ }^{6}$.

The first assumption holds that the volume of the water tongues have to be equal as well, but the volume is not distributed the same along the vertical axis; configuration (2) beholds more volume of water above the crest than configuration (1).

The empirical coefficient $c^{\prime}{ }_{h, 2}$, was determined to be 0.33 or 0.15 for both dike configurations, Schüttrumpf and Van Gent (2003). With these values the new coefficient can be determined, related to the outer slope angle, see Eq 10.

$$
c_{h, 2 \%}^{\prime}=\frac{9 \cdot 10^{-3}}{\sin ^{2} \alpha} \text { and: } \frac{a^{2}}{b^{2}}=9 \cdot 10^{-3}
$$

With the new coefficient $c_{h, 2 \%}^{\prime}$, the coefficient $c^{\prime}{ }_{\mu, 2} \%$ can be determined with the relation between maximum flow depth and maximum velocity (see Eq 7).

\footnotetext{
${ }^{6}$ These assumptions cannot be physically proved at this moment. The flow depths in point $S$ and $P$ can also be different and the shape of the overtopping tongue might not be curved as well, however the difference between the flow depths in point $S$ and $T$ should be a factor 2.2 in relation to Schüttrumpf and Van gent (2003).
} 


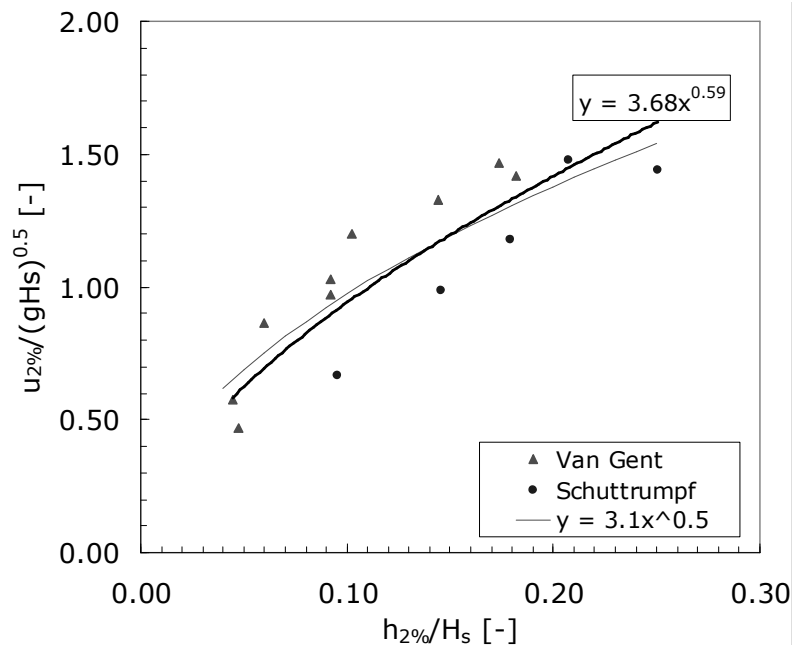

Figure 8. Relation maximum velocity and maximum flow depth

Figure 8 shows a fit (thick line) between the $2 \%$ velocity and flow depth data of Schüttrumpf and Van Gent. The fit is a function to the power 0.58, however the theory of maximum flow depth and maximum velocity states that the relation between both unities must be a square root function, (see equation 7). Figure 8 shows this relation drawn with a thin line, in such a way that it correlates as good as possible with equation 9. Thus the relation between maximum flow depth and maximum velocity on the crest can now be described by equation 11 :

$$
\frac{u_{2 \%}}{\sqrt{g H_{s}}}=3.1\left(\frac{h_{2 \%}}{H_{s}}\right)^{0.5} \text {, for } 0.03<\frac{h_{2 \%}}{H_{s}}<0.25
$$

With the relation in equation 11 the empirical coefficient $a$ can be determined using equations 10 and 11 . With $a^{2} / b^{2}=9 \cdot 10^{-3}$ and $b=3.1$ makes: $a$ $=0.30$. The empirical coefficient $c^{\prime}{ }_{u, 2 \%}$ becomes:

$$
c_{u, 2 \%}^{\prime}=\frac{0.30}{\sin \alpha}
$$

The coefficients on the seaside of the crest for the two different dike models become:

$c_{u, 2 \%}^{\prime}=0.30 / \sin \alpha_{1}=1.24$ for a configuration with an outer slope of 1:4.

$c_{u, 2 \%}^{\prime}=0.30 / \sin \alpha_{2}=1.83$ for a configuration with an outer slope of 1:6. 
These values of the coefficients differ from the ones found by Schüttrumpf and Van Gent and found in the present study, but the values of the coefficient $c^{\prime}{ }_{u, 2 \%}$ listed above, have been based on the flow depth coefficient $c^{\prime}{ }_{h, 2 \%}$ and on the relation between maximum flow depth and maximum velocity. This relation is considered to be more reliable than a determination with only maximum velocity data. Length is an integral of velocity over time, and therefore a more consistent unity.

\section{The influence of the crest}

On the crest friction takes place, the maximum velocities and maximum flow depths will therefore decrease over the crest. In the formulae of Schüttrumpf and Van Gent an exponential function has been used, see equations 3 and 4.

The position on the crest $x_{c}$ has been made dimensionless by the crest width $B_{c}$ in equation 3. This means that in this relation the flow depth at the landward side of the crest does not depend on the crest width. In the present study a relation has been found for the flow depth on positions $x_{c}$ on the crest made dimensionless by the wave length $L_{0}$.

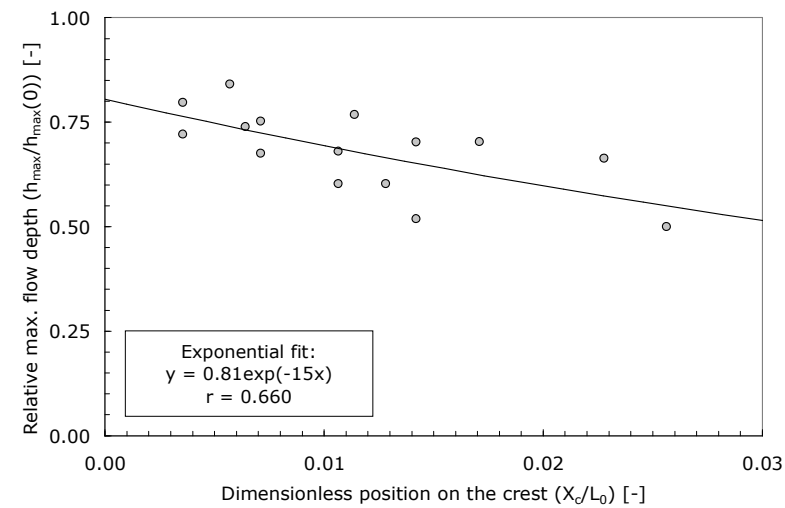

Figure 10. Alteration of maximum flow depth on the crest for regular waves

The decrease of the maximum flow depth on the crest has been plotted in Figure 10. The maximum flow depth per position $x_{c} / L_{0}$ has been divided by the maximum flow depth on the seaside of the crest. The first measuring position is on $x_{c}=0.5 \mathrm{~m}$ behind the beginning of the crest. One can see that at this first location behind the beginning of the crest, the maximum flow depth has decreased with approximately $25 \%$ in comparison to the seaside of the crest. This is due to the transition of the water from the outer slope onto the crest. The direction of the water needs to change from the direction parallel to the outer slope into the horizontal direction on the crest. This transition requires some time and space. The relation for the maximum flow depth on the crest needs to be independent of this transition. The exponential fit in Figure 10 therefore only 
depends on maximum flow depths on the crest behind this transition. Equation 3 becomes equation 13 :

$$
\frac{h_{2 \%}\left(x_{c}\right)}{h_{2 \%}\left(x_{c}=0\right)}=c_{\text {trans }, h} \exp \left(-c_{h, 2 \%}^{\prime \prime} \frac{x_{c}}{\gamma_{c} L_{0}}\right)
$$

Where:

$$
c_{\text {trans }, h}=\text { influence due to transition from outer slope to crest }
$$

$$
\gamma_{c} \quad=\text { friction factor on the crest }(=1 \text { for a smooth surface })
$$

The maximum velocity depends on the maximum flow depth on the crest, see equation 4 . The transition factor has already been implemented in the flow depth and therefore does not have to be implemented in the velocity formula. Equation 4 will be changed into equation 14. In this equation a different friction coefficient is used. The surface of the model in the tests is considered to be smooth $\left(\gamma_{c}=1\right)$.

$$
\frac{u_{2 \%}\left(x_{c}\right)}{u_{2 \%}\left(x_{c}=0\right)}=\exp \left(-c_{u, 2 \%}^{\prime \prime} \frac{x_{c}}{\gamma_{c} h_{2 \%}\left(x_{c}\right)}\right)
$$

The coefficients have been determined for regular waves (see Table 4). The coefficients for irregular waves are expected to be almost the same.

\begin{tabular}{|l|l|l|}
\hline \multicolumn{3}{|c|}{ Table 4. Empirical coefficients on the crest for regular waves } \\
\hline$C_{\text {trans, } h}$ & $c^{\prime \prime}, 2 \%$ & $c^{\prime \prime}{ }_{u, 2 \%}$ \\
\hline 0.81 & 15 & 0.042 \\
\hline
\end{tabular}

\section{OVERTOPPING TIME}

The overtopping time is the time that an individual wave passes a certain location on the revetment. The overtopping time $T_{o v t, 2 \%}$ is the overtopping time exceeded by $2 \%$ of the incoming waves. The larger the volume of an overtopping event has been, the longer the overtopping time $T_{\text {ovt }}$ will be. The (maximum) overtopping time is useful when one wants to describe the variation of flow depths and velocities in time. In other words; a relation between the maximum flow depth, maximum velocity and the corresponding overtopping time.

A relation for the maximum overtopping time can be based on the remainder of the wave run-up, thus the difference between the fictive wave run-up and the crest freeboard. This can be best visualised with the dike models from the example used above. Figure 12 is a combination of Figures 3 and 4. The remainder of the wave run-up has been indicated with the letter $A$. The vertical velocity component of the water is in both dike models the same. Therefore the time that the water is flowing between $Q-R$ and $T-R$ is the same as well. 


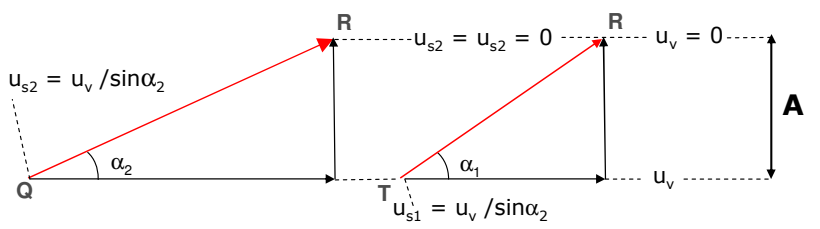

Figure 12. Velocity components of the example

The time water flows between $Q$ and $R$ and $T$ and $R$ can be determined with two motion equations for velocity and distance, see equation 15 :

$$
\left.\begin{array}{l}
A=u_{v} t-\frac{1}{2} g t^{2} \\
0=u_{v}-g t
\end{array}\right\} t=\sqrt{\frac{A}{2 g}}=\sqrt{\frac{z_{2 \%}-R_{c}}{2 g}}
$$

The formula for the $2 \%$ overtopping time is related to the square root of the remainder of the wave run-up. With $2 g$ as a constant value, the $2 \%$ overtopping time can be described by equation 16 . The overtopping time has been made dimensionless with the spectral wave period $T_{m-1.0}$.

$$
\frac{T_{o v t, 2 \%}\left(x_{c}=0\right)}{T_{m-1.0}}=c_{T o v t, 2 \%}^{\prime} \sqrt{\frac{z_{2 \%}-R_{c}}{\gamma_{f} H_{s}}}
$$

Where:

$c^{\prime}{ }_{T o v t, 2 \%}=$ empirical coefficient

\section{The influence of the crest}

The overtopping time on different positions on the crest is described by equation 17. Generally, the velocity and flow depth decrease on the crest, while the overtopping time increases.

$$
\frac{T_{o v t, 2 \%}\left(x_{c}\right)}{T_{o v t, 2 \%}\left(x_{c}=0\right)}=\left(1+c_{T o v t, 2 \%}^{\prime \prime}\left(\frac{x_{c}}{L_{0}}\right)\right)
$$

Where:

$c^{\prime}{ }^{\text {Tovt }, 2 \%=\text { empirical coefficient }}$

The empirical coefficients for both Eq. 15 and 16 are presented in Table 5. 


\section{VARIATION IN TIME}

The variation in time of both the velocity and the flow depth can roughly be estimated as a linear function. As a result the graphs are triangular shaped. With discharge $q=h \cdot u[\mathrm{~m} 3 / \mathrm{s} / \mathrm{m}]$ can be visualized in Figure 13. One can see that the product of two triangles returns in a curved shape. The integral of the discharge over time is equal to the volume of the overtopping wave. Equation 18 shows a dimensionless to describe the volume of the overtopping wave.

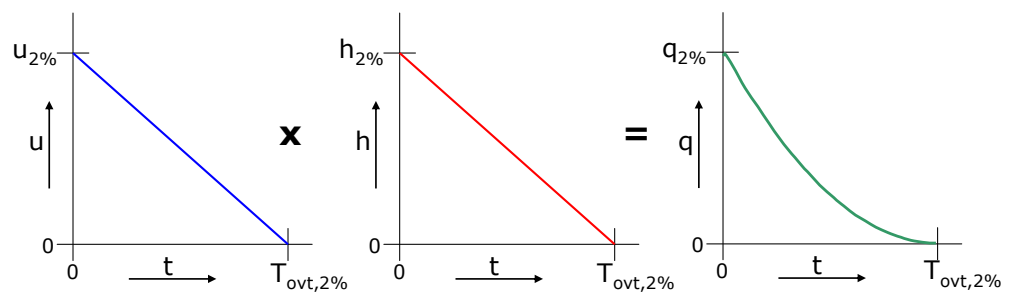

Figure 13. The product of velocity and flow depth in leads to the discharge in time

$$
\frac{V_{2 \%}}{H_{s}^{2}}=c_{s} \frac{u_{2 \%}}{\sqrt{g H_{s}}} \frac{h_{2 \%}}{H_{s}} \frac{T_{o v t, 2 \%}}{T_{m-1.0}}
$$

The coefficient $c_{s}$ can be determined empirically and should equal $c_{s}=1 / 3$ if the flow depth and velocity in time is linearly decreasing. In Figure 14 the coefficient is determined to be $c_{s}=0.40$.

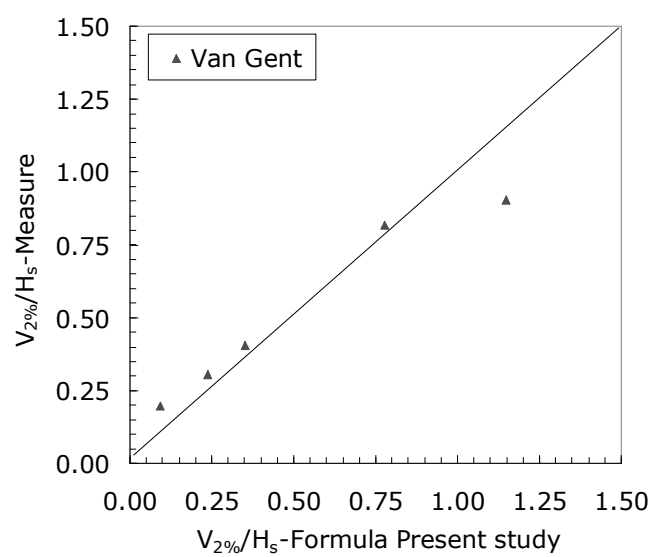

Figure 14. Measured against determined volumes, with $c_{s}=0.40$

The difference between $c_{s}=0.33$ and $c_{s}=0.40$ is very small. The variation of velocity and flow depth in time can be assumed to be linear (triangular shaped). Equation. 18 can be used for the determination of the volume of an overtopping event. 


\section{CONCLUSIONS}

The velocity of high turbulent, non stationary, air containing flow appeared to be very difficult to measure. The empirical velocity coefficient found by Schüttrumpf (2001b) is therefore too low, for that matter not only the flow depths, but also the velocities that occurred during Schüttrumpf's tests were higher than by Van Gent.

The outer slope turned out to be of great importance in the flow depths and velocities on the crest. This is new knowledge. The empirical coefficients appeared to be dependent on the outer slope steepness. Therefore formulae for maximum flow depth and velocity were adapted: the coefficients are written as a function of the outer slope angle. Subsequently a formula for the overtopping time has been created, based on the difference between fictive wave run-up and crest freeboard. The overtopping time appeared not to be a function of the outer slope. The variation of flow depth and velocity in time can be approached with a linear function.

Also new equations for flow depth and velocity on the crest are presented. The present study proposes to implement an transition parameter. This transition causes flow depths and velocities to decrease with approximately $20 \%$.

\section{ACKNOWLEDGMENTS}

The development of this work took place with data from large scale tests in the GWK in Hannover and data from small scale model tests by WL Delft Hydraulics. The GWK data were obtained within the project "Loading of the inner slope of seadikes by wave overtopping" (Bundesminsisteriumf für Forschung und Technologie KIS 009). The data from WL were obtained within the context of Delft Cluster, project "Processes related to breaching of dikes".

\section{REFERENCES}

Van Gent, M.R.A. (2002). Low-exceedance wave overtopping events, WL Delft project id. DC030202/H3803.

Van der Meer, J.W., Snijders, W. and Regeling, E. (2006), The wave overtopping simulator. Proc. $30^{\text {th }}$ International Conference on Coastal Engineering, (4654-4666), San Diego, USA.

Overtopping Manual (2007) EurOtop; Wave overtopping of sea defences and related structures - Assessment manual. EA-Environmental Agency, UK; ENW-Expertise Netwerk Waterkeren, NL; KFKI-Kuratorium für Forschung im Küsteningenieurwesen, DE. See: www.overtopping-manual.com.

Schüttrumpf, H.F.R. (2001a), Wellenüberlaufströmung bei See-deichen, Ph.D.thesis, Technical University Braunschweig.

Schüttrumpf, H.F.R., Oumeraci, H., Möller, J., Kudella, M., (2001b), Loading of the inner slope of seadikes by wave overtopping, Leichtweiss Institut für Wasserbau \& Technical University Braunschweig.

Schüttrumpf, H.F.R. and Van Gent, M.R.A. (2003), Wave overtopping at seadikes, Proc. $3^{\text {rd }}$ Coastal Structures Conference, Portland, USA. 